\title{
GAUGING AUDIENCES' MESSAGE RECALL THROUGH BRAND ELEMENT PLACEMENT IN TELEVISED COMMERCIALS
}

\author{
Kashif Riaz ${ }^{1}$ \\ Preston University

\section{Dr. Rukhsar Ahmed ${ }^{2}$}

\begin{abstract}
Purpose: This study helps to understand the successful path of micro-financing, which can plays a vital role in poverty alleviation in Pakistan.

Methodolgy/Sampling: To collect data authors of this paper visited different microfinance institutions (MFIs) like Tameer Micro Financing Bank and Khushali Bank Limited in Karachi. A structured questionnaire was designed for data collection of consumers of microfinance. Statistical data of 100 samples showed $46 \%$ of respondents acquired loan for agricultural purposes while 54\% loans were business based.

Findings: It is observed that male respondents are higher than female. Regression model showed $38 \%$ variation in consumer preference regarding the microfinance services. Statistic in the ANOVA shows the significance of model. The coefficient of MFI's Approach with negative sign indicates an inverse relationship with that of consumer preferences. It means that MFI agents do not give proper value to the targeted consumers. Finally the amount of loan and interest charged by the MFI's is also having a negative impact on the consumers of micro-finance.

Practical Implications: This study deliver statistical evidence of utilization of funds as well as the consistency of gathered data. Work showed that responded are need to be aquired more knowlwdge about the microfinance services in Pakistan..
\end{abstract}

Key Words: MFIs, Microfinance, Customer Preferences, Pakistan.

* The material presented by the author does not necessarily portray the viewpoint of the editors and the management of the Institute of Business \& Technology (IBT)

1. Kashif Riaz :kashriz@gmail.com

2. Dr. Rukhsar Ahmed :RukhsarAhmed2000@yahoo.com

(C) IBT-JBS is published by the Institute of Business and Technology (IBT). Main Ibrahim Hydri Road, Korangi Creek, Karachi-75190, Pakistan. 


\section{INTRODUCTION}

Brand comprises of name, term, sign, symbol, design or a combination of the same, initiallyused for the purpose of identification (Keller L. C., 2003).Brands now have become more complex both in term of its meaning and functions, instead of being used for identification purposes only it is now considered as a semiotic engine that is constantly adding meaning and value (Heilbrunn, 2006).Brands and consumers have a two way commitment where consumers offer their trust and loyalty and where brands promise to behave in a certain manner which is used by consumers to portray their self-image, traits and values. Brands in todays' world is not consumed solely for its functional traits rather it is used for construction and maintenance of identity by the consumers (Elliott \& Davies, 2006).

A lot of investments have been made by companies in advertising to develop a good brand impression in the minds of the consumers that will yield profitability to the organization(Sacharin, 2001). Brand impressions formed in consumers' mind provides benefit to the firm and one these benefits is that these impressions have been found to increase efficiency and effectiveness of all marketing and communication efforts of the company because of its capability to capture attention and obtain place in memory (Bagozzi, Rosa, Celly, \& Coronel, 1998). Many expert believe that "the power of marketing is eroding ... from lack of attention" (Sacharin, 2001) therefore brands have evolved into a strategic asset which is essential for the long-term performance of the company (Sriram, Balachander, \& Kalwani, 2007)

Brand image is a combination of both visual and audio elements of the brand including name, color, slogans, shapes, logo, images, symbols, characteristics, jingles and others; these elements attempts to enhance recall by assisting in brand identification along with related information about the brand, especially in situations where consumers are confronted with problems that requires solution. Consumer learning and understanding of these elements is developed through their direct and indirect experience. Consumers' direct experience comes from utilization of the product whereas the indirect experience occurs through brand elements exposures in respective advertisements done on various mediums (Singh, Goodhardt, \& Ehrenberg, 2004). Researchers have found that these elements are extremely helpful in generating brand recognition and recall furthermore not only they have made consumers' selection process more efficient but have also been found to create preference (Morrow, 1992).

Elements and their impact on consumers' mind have been researched in the past however few researches have been done in order to rationalize the use of brand elements in advertisements in order to enhance the attention, transference and recall of the advertised message and brand (Wanke, Andreas, \& Dorothea, 2007). It is therefore important to understand the impact of these elements on recall and whether these elements impact differently towards generating memory structures.

\section{LITERATURE REVIEW}

Consumers in developing a brand image will process all the related information that they get exposed to through the companies' marketing efforts and combine it with their experience of the brand. This developed brand image is usually considered during the product selection process done by the consumers at the time of purchase (Keegan, Moriarty, \& Duncan, 1995). Consumers regularly demonstrates attributes of their personality through their choice of brands thus creating a strong association with their chosen brand. Marketing efforts are made to create, maintain, protect, enhance these brands and its association with consumers in order 
to inculcate a deeper brand meaning in consumers' mind(Aaker, 1991)(Kotler, 2002). Consistency in company's marketing efforts results in higher brand associations which in turn will provide value by enhancing information processing and increasing shopping efficiency, this is achieved because these efforts enhances consumers' confidence in the decision making process, reinforces their decision and contributes towards building self-esteem (Bagozzi, Rosa, Celly, \& Coronel, 1998). Strong brand associationshave also been found to createa higher level of brand knowledge which in turn motivates the consumers to give a positive response towards the marketing efforts/activities of that brand (Keller K. L., 1993).

Marketers have used brand elements, specially brand name and logo to communicate and portray brand identity to consumers (Aaker, 1991)(Henderson \& Joseph, 1998)(Shimp, 2003). Brands create a strong psychological impact on the consumers and some researchers have demonstrated that due to effective advertisements some brands have been able to create a place in memory during the early childhood ages which has influenced the decision making process when these children have come to age. Marketers will always attempt to capitalize on the created image through marketing efforts because consumers have associated themselves with their brands and have developed an emotional attachment which becomes a very influential factor in their decision making process (Kathryn, Michael, \& George, 2007).

Brands constitute of elements like name, shape, color, slogan, logos or images, fonts, characters, jingles or music that are presented in advertisements and other communication through visual and audio mediums. The use of these elements in advertisements have been found helpful in identification and recall of the brand at the relevant time by the consumers(Gaillard \& Romaniuk, 2006). There have been many arguments in support of brand elements being prominently placed in advertising (Kapferer, 1992)(Keller L. C., 2003). "The most important thing to remember in advertising is to focus on identification of the brand... It sounds simple; it isn't. Play the brand front and center" (Moriarty, 1986). The use of brand elements in advertising refers to the prominence and conspicuity given to these elements in advertisements and other corporate communication. It is important that these brand elements should standout in comparison to other visual and audio elements in the advertisement. In advertisements these brand elements should appear larger, central and distinctive from the background and should also have audio support where possible (Palmer, 1999).

Advertisements should show these brand elements clearly and loudly, as research studies have shown that advertisements displaying prominent brand elements have resulted in higher attention levels which helps in achieving the desired communication effects and enhances consumers recall capabilities (Smith, 1973). It is therefore has become important to determine whether the use of brand elements in televised commercial impacts on the respondents' capability to recall the advertised message or not. This research attempts to distinguish between both types of recall that is when consumers were probed or provided hint, generally referred to as aided recall and when consumers recall the information without any assistance, referred to as unaided recall. The following hypothesis were developed and tested for this purpose:

\section{$H_{1}$ : Exposure to brand elements increases unaided recall of the advertised message}

$\mathrm{H}_{2}$ : Exposure to brand elements increases aided recall of the advertised message

Studies have shown that situations where consumers are familiar with the brand elements have paid higher attention towards the advertisement which in turn resulted in effective recall. Moreover the use of different brand elements, the visual size of these brand elements 
along with other attributes of the advertisement body have been found to significantly influence the level of attention, transference of advertised message and its recall(Pieters \& Michel, 2004).

Images of brand elements that are used in advertising act as powerful memory triggers because they are rich in stimuli and mainly rely on peripheral attention furthermore these images are more elaborative and distinctive to the viewers (Childers, Heckler, \& Houston, 1986).Related studies have shown that brand elements must be included in the advertisement so that viewers generate awareness about the brand and process the brand in memory. In absence of brand elements there will be no awareness about the brand and such advertisements will have limited or no impact on the viewers (Baker, Honea, \& Russel, 2004). Many advertisements fail to create linkage between the message and the brand in the mind of the consumer and as a result high proportion of viewers either incorrectly recall or are completely unable to recall the brand after viewing the commercial (Rossiter \& Bellman, 2005).

There have been instances where viewers have developed a positive association with commercials however failed to link it with the brand itself. Hence it is extremely important to ensure that during the design and execution stage of the advertisement, the response, association and emotion developed by the consumers after viewing the advertisement is linked with the brand and not with the advertisement itself (Baker, Honea, \& Russel, 2004).

Prominent brand elements in comparison to other visual elements of the advertisement are able to capture more attention for the brand and its advertisement, which is the first and foremost requirement of achieving higher recall levels and the desired brand-communication effect. It has also been observed by researchers that association with the brand elements encourages viewers to pay more or less attention to the advertisement and its elements depending on whether they have positive or negative association with the brand and its elements (Pieters \& Michel, 2004). The associative learning theories states that previous association about the brand and its elements will play a key role in establishing brand nodes in memory and there will be a link between existing knowledge and the new information being processed. If a brand element enjoys a favorable association in consumers' mind then it is likely that in advertisements where the said element is prominently usedor visually apparent, all information presented in that advertisement will be linked or influenced by that association (Baker, Honea, \& Russel, 2004).

Researchers have shown that viewers' association with brand elements will impact on the information processing of the advertised message and ultimately recall. It is therefore important to determine if different brand elements impact differently towards unaided and aided recall of the advertised message and whether the elements that may be found impactful in unaided recall are also impactful in aided recall or vice versa, for this purpose the following hypothesis are tested:

$H_{3}$ : Brand elements impact differently towards unaided recall of the advertised message

$\mathrm{H}_{4}$ : Brand elements impact differently towards aided recall of the advertised message

\section{METHODOLOGY}

The research model developed for this study, first determined whether or not there is any influence of brand elements on unaided and aided recall of the advertised message that was shown to the selected sample. The model is further extended to differentiate the impact of each of the selected brand elements towards recall and thus be able to answer that whether 
different brand elements impact differently towards unaided and aided recall of the televised message communicated in commercials. The brand elements selected for this study were brand name, character, logo and slogan. The differentiation study done, attempts to distinguish the impact of these four brand elements on the recall capabilities of the viewers. The developed research model has also been summarized in Figure 1.

Comparison was made with respect to the sample's ability to correctly recall the advertised messages that were communicated in the shown commercials with and without aid. The recall scores obtained by the group that were exposed to the brand elements in the shown commercials are compared with the recall scores of the group that were shown commercials in which the brand elements were digitally removed. The respondents' ability to recall is compared through a t-two samples mean test which attempts to compare the scores of both

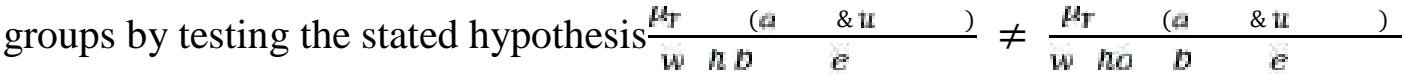

The second part of the model compares the selected brand elements' ability to influence recall of the advertised messages that were shown in the commercials. The sample were divided into four groups, the groups were then exposed to one brand element each and their recall scores were recorded. The difference in treatment of the groups and its impact is measured through ANOVA which basically attempts to prove that $r$ s $g{ }_{1} \neq$ $r \quad s \quad g \quad{ }_{2} \neq r \quad s$ or $g \quad 3 \neq r \quad s \quad g \quad{ }_{4}$. ANOVA is used to determine the impact of different brand elements on the respondents' capability to recall the messages shown in the advertised commercials with or without aid and prove that the $S S T$ calculated through the expression $\sum n(x-\bar{x})^{2}$ will be higher due to the stated treatment to the groups and thus results in higher $F$ value.

\section{a. Sampling Methodology}

The sample selected for this study comprised of four groups of 25 respondents each, probabilistic technique of simple random sample was used for sample selection. The simple random sampling technique is calculated by using the under shown formula

$$
\begin{gathered}
P(n)=1-\frac{N-1}{N} \cdot \frac{N-2}{N-1} \cdots \cdots \cdot \frac{N-n}{N-(n-1)} \\
\quad c \quad=1-\frac{N-n}{N}=\frac{n}{N}
\end{gathered}
$$

University level students were selected in order to obtain demographic homogeneity. The first group of 25 was abstracted from the batch of 37 students and resulted in the probability of $67.56 \%$ also shown in the formula $P_{-} 1=25 / 37$ or $67.56 \%$. The second group of 25 was selected from a batch of 33 resulted in the probability of $75.75 \%$ shown in formula as well P_2 $=25 / 33$ or $75.75 \%$. The third group selection of 25 also followed the similar pattern and was selected from the group of 41 resulting in the probability of $60.97 \%$ and finally the forth group was selected from 29 students which resulted in the selection probability of almost $86 \%$. The calculated probability of all groups is presented as under

$$
P_{1}=\frac{25}{37} 0 \quad 67.56 \%\left|P_{2}=\frac{25}{33} 075.75 \%\right| P_{3}=\frac{25}{41} 0 \quad 60.97 \%\left|P_{4}=\frac{25}{29} 0 \quad 86.20 \%\right|
$$

\section{b. The Experiment\& Data Collection}

The first experiment was conducted by exposing two groups out of the total four groups with televised commercials, the first group was exposed to commercials containing brand elements namely brand name, logo and symbols, slogans and characters that were originally 
present whereas the second group was exposed to the same televised commercials but the brand elements were digitally removed.

The sample was shown a series of commercials after which they were required to fill a questionnaire that attempted to gage the aided and unaided recall of the televised message. The response obtained are cross compared between both groups by using t-two sample mean statistical techniques in order to determine whether brand elements have any influence on aided and unaided recall of the televised message. Respondents were asked to freely express whatever information they can recall about the shown advertisements, their responses are graded on a four point rating scale ranging from completely unable to recall to completely able to recall the message.

The aided recall capabilities of the respondents with and without the exposure to brand elements are measured through multiple choices, where respondents were provided clues with respect to the messages that they were exposed to and were required to select the appropriate choice which they thought best represented their response to the stated questions. Their responses are measured on a three point scale based on their ability to recall correctly, incorrectly or not been able to recall at all.

The second experiment attempted to determine whether different brand elements impact differently towards unaided and aided recall, for this purpose all four groups were selected. Each group was shown one of the four selected brand elements namely brand name, character, logo or slogan. The respondents were asked to freely express all the information that could recall about the shown advertisements. The unaided recall is measured through open ended responses where responses provided are rated against a scale which ranged from complete inability to recall the advertised message to their ability to fully recall the advertised message. The aided recall capability of the respondent was measured by asking the respondent to select the appropriate choice which they believe best represented their answer to the questions asked. The close ended questions designed to measure aided recall were related to the messages communicated in the advertised commercials. The responses to closed ended questions are measured against a three point rating scale that ranged from the sample's ability to correctly recall, incorrectly recall or not been able to recall at all.

\section{RESULT, ANALYSIS AND FINDINGS}

The first hypothesis tested was the mean score obtained by both the groups with respect to their ability to correctly recall the advertised messages without any probe. If by comparison, score obtained by group which was exposed to the brand elements were higher as compared to the scores obtained by the other group which was not exposed to the brand elements then it can be proved that brand elements have influenced the unaided recall capabilities of the group. The statistical computation resulted in a calculated paired sample t test value of 2.26 which is very significant when compared with the tabulated value.

The t-test value is higher than the tabulated value therefore it is concluded that presence of brand elements does influence the unaided recall capabilities of the respondents. The detailed descriptive and test statistics are presented in table 1.

Same test was repeated for the aided recall responses of the sample, one group was exposed to commercials which contained the brand elements whereas the other group was exposed to commercials in which brand elements were digitally removed. A series of close ended structured questions were asked to gage the respondents' aided recall capabilities.

However, the t-test value proved insignificant and therefore this study fails to reject the null hypothesis meaning that no significant difference is found between both groups and on their ability to recall the message when aided. Therefore this research is unable to convincingly 
prove that exposure to brand elements have resulted in higher aided recall capabilities. Detailed descriptive and test statistics are presented in table 2.

\section{a. Differences in unaided recall due to brand elements}

Experiments were performed in order to determine whether different brand elements impact differently towards unaided and aided recall of the advertised message. The data was collected from all four groups through asking open ended questions about the messages shown in commercials, where respondents were allowed to freely express all the information that they can recall from the shown commercials.

Impact of brand elements on unaided recall is determine through differences in treatment that comes from exposure to different brand elements. Each of the four groups were exposed to single brand element that was either brand name, character, logo or slogan. The other brand elements present in the advertisements were digitally removed. The collected data is analyzed through ANOVA and is also presented in table 3 and table 4.

The ANOVA test revealed a $p$ value $0.001<0.05$, furthermore the $F$ calculated value is 6.082 which is significantly higher than the tabulated value, therefore $h_{\square}$ is rejected. The obtained result strongly demonstrates that different brand elements yield higher recall of the advertised message when used in TV commercials. The test also reveals that the two most impacting brand elements on unaided recall capabilities of the respondents are brand name and character.

\section{b. Difference in aided recall due to brand elements}

The four groups that were exposed to single brand element that was eitherbrand name, characters, logo or slogans, were presented with multiple choice questions and were asked to select the response which they think best represented their response to the questions presented in the questionnaire. The process attempted to record the aided recall capabilities of the respondents, the data from these groups is crossed compared through ANOVA in order to determine whether different brand elements impact differently towards aided recall of the advertised message. The descriptive statistics and ANOVA calculations are presented in table 5 and table 6.

ANOVA test provides $\mathrm{F}$ calculated value of 5.89, which proves significantly that exposure to different brand elements has impacted differently towards aided recall. Furthermore the $p$ value of 0.001 isless than 0.05 and therefore rejects the null hypothesis. This significantly proves that the use of brand elements results in achieving communication effectiveness of the advertised message. Among the four band elements tested slogan has shown to be the most effective element to impact on memory and be able to achieve a higher recall level when respondents were probed.

\section{LIMITATIONS AND AREA FOR FURTHER RESEARCH}

Limitations of this study provides opportunities for further research in the area. Firstly this study attempted to determine whether brand elements play any role in the recall of the messages shown in televised commercials and does not consider the existing brand knowledge and attitude that the brand might already be enjoying and which may potentially impact on the communication effectiveness of the advertised message and ultimately recall(Celsi \& Olson, 1988), (Erdem, et al., 1999), (Pieters \& Michel, 2004).

Secondly the duration of the advertised message and the duration of the display of the brand elements within the advertisement itself is also not considered in this research. The frequency 
and the duration of the elements exposure contributes toward effective communication of the advertised message and is another potential area for further studies (Baker, Honea, \& Russel, 2004)

\section{CONCLUSION AND RECOMMENDATIONS}

Advancement in the field of neuroscience has provided various tools which can more accurately gage the changes in the brain and more specifically in memory structure, these methods are more accurate and are able to record changes in memory more deeply as compared to the self-reporting mechanism. Advertisements on web pages and other carriers are also gaining significance because they are able to transmit messages visually similar to television. The application of the theories and knowledge gained about the impact of brand elements on communication effectiveness and ultimately recall may prove useful not only in achieving effective communication through commercials aired on television but also on mediums having similar transmission capabilities. The model proven in this study supports the belief of prominently using brand elements in commercials and provides strong arguments against the critics of the theory furthermore it also improves understanding of how these elements impact differently on achieving communication effectiveness. The findings will also be helpful in the advertisement designing stage specially in selecting brand elements that should be prominently shown in the advertisement to achieve higher recall levels.

\section{ACKNOWLEDGEMENT}

First of all with a profound gratitude, we are thankful to Almighty Allah forgiving us success, knowledge and understanding without which we would not been capable of completing this research paper.

We are also profoundly grateful to all our family members whose endurance and understanding have played a significant role in our success by sacrificing the important family time and supporting us all over the research work.

We are finally thankful to the editor, reviewers and IBT especially who provided us with the opportunity to publish our research paper in this esteemed journal.

\section{REFERENCES}

Aaker, D. A. (1991). Measuring Brand Equity Across Products and Markets. California Management Review, 38(Spring), 102-120.

Bagozzi, R., Rosa, J., Celly, K., \& Coronel, F. (1998). Marketing Management. Upper Saddle River: Prentice Hall.

Baker, W. E., Honea, H., \& Russel, C. A. (2004). Do not wait to reveal the brand name: the efect of brand-name placement on television advertising effectiveness. Journal of Advertising, 33(3), 77-85.

Celsi, R. L., \& Olson, J. (1988, September). The role of involvement in Attention and Comprehension Process. Journal of Consumer Research, 15, 210-224.

Childers, T., Heckler, S., \& Houston, M. (1986). Memory of the visual and verbal components of print advertisements. Psychology \& Marketing , 3((3)), 137-149.

Elliott, R., \& Davies, A. (2006). Symbolic Brands and Authenticity of Identity Performance. Brand Culture. 
Erdem, T., Swait, J., Bronizrczyk, S., Chakravarti, D., Kapferer, J.-N., Keane, M., . . . Zettelmeyer, F. (1999). Brand Equity, Consumer Learning and Choice. Marketing Letters, 10(3), 301-318.

Gaillard, S. E., \& Romaniuk, J. (2006). Measuring brand distinctive elements in an in-store packaged goods consumer context. European Marketing Academy Conference $(E M A C)$. Athens.

Heilbrunn, B. (2006). Cultural Branding between Utopia and A-topia. Brand Culture, 1-10.

Henderson, P. J., \& Joseph, C. A. (1998, April). Guidelines for Selecting or Modifying Logos. Journal of Marketing, 62, 14-30.

Kapferer, N. (1992). Strategic Brand Management (2 ed.). New York: The Free Press.

Kathryn, A. B.-L., Michael, S. L., \& George, M. Z. (2007, April). Using Childhood Memories to Gain Insight into Brand Meaning. Journal of Marketing, 71, 45-60.

Keegan, W., Moriarty, S., \& Duncan, T. (1995). Marketing. Englewood Cliffs: Prentice Hall.

Keller, K. L. (1993). Conceptualizing, measuring and managing consumer-based brand equity. Journal of Marketing, 57, 1-22.

Keller, L. C. (2003). Strategic Brand Management. New Jersey: Prentice Hall Inc.

Kotler, P. (2002). Marketing Management (11 ed.). New Jersey: Prentice Hall Inc.

Moriarty, S. (1986). Creative Advertising: Theory and Practice. . NJ: Prentice Hall.

Morrow, D. J. (1992). An Image Makeover. International Business, 5(3), 66-68.

Palmer, S. E. (1999). Vision Science: Photons to Phenomenology. Cambridge MA: A Bradford Book.

Pieters, R., \& Michel, W. (2004, April). Attention Capture and Transfer Advertising: Brand Pictorial and Text-Size Effect . Journal of Marketins , 68, 36-50.

Rossiter, J. R., \& Bellman, S. (2005). Marketing Communications: Theory and Applications. Frenchs Forest: Pearson Education.

Sacharin, K. (2001). Attention! How to Interrupt, Yell, Whisper and Touch Consumers. New York: John Wiley \& Sons.

Shimp, T. A. (2003). Advertising, Promotion, \& Supplemental Aspects of Integrated Marketing Communications. Thomson, South-Western.

Singh, J., Goodhardt, G., \& Ehrenberg, A. (2004). Loyalty to SKU-based product variants. Journal of Customer Behavior, 3(2), 123-132.

Smith, C. S. (1973). How to Get Big Results from a Small Advertising Budget. New York: Hawthorn Books.

Sriram, S., Balachander, S., \& Kalwani, M. U. (2007, April). Monitoring the Dynamics of Brand Equity using Store-Level Data. Journal of Marketing, 71, 61-78.

Wanke, M., Andreas, H., \& Dorothea, S. (2007). Brand Name Influence on Brand Perception. Psychology \& Marketing, 24(1), 1-24. 


\section{APPENDIX}

Figure 1: Research Model for brand element exposure

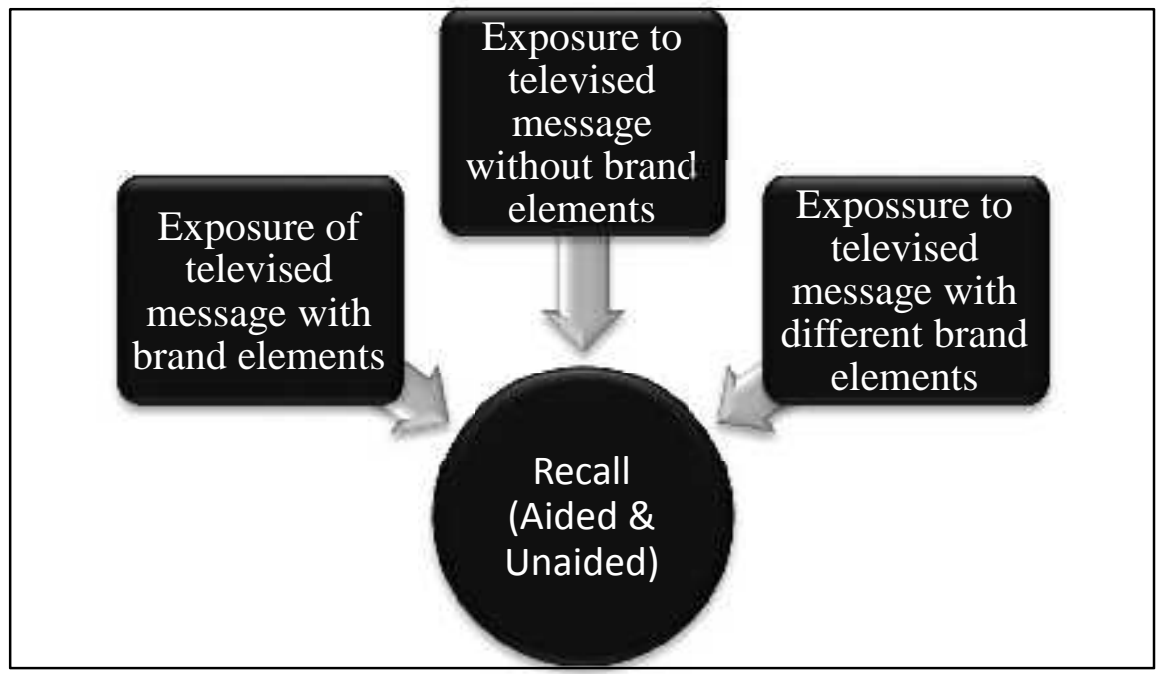

\begin{tabular}{|c|c|c|c|c|c|c|c|c|c|}
\hline \multicolumn{10}{|c|}{ Table 1: Paired Samples Test - Unaided Recall } \\
\hline & & \multicolumn{5}{|c|}{ Paired Differences } & \multirow[t]{3}{*}{$\mathrm{t}$} & \multirow[t]{3}{*}{ df } & \multirow[t]{3}{*}{ Sig. (2-tailed) } \\
\hline & & \multirow[t]{2}{*}{$\begin{array}{c}\text { Mea } \\
n\end{array}$} & \multirow[t]{2}{*}{$\begin{array}{l}\text { Std. } \\
\text { Deviat } \\
\text { ion }\end{array}$} & \multirow[t]{2}{*}{$\begin{array}{l}\text { Std. } \\
\text { Error } \\
\text { Mean }\end{array}$} & \multicolumn{2}{|c|}{$\begin{array}{l}\text { 95\% Confidence } \\
\text { Interval of the } \\
\text { Difference }\end{array}$} & & & \\
\hline & & & & & Lower & Upper & & & \\
\hline Pair 1 & $\begin{array}{c}\text { UnaidedRecal } \\
\text { lG1 - } \\
\text { UnaidedRecal } \\
\text { IG2 }\end{array}$ & -2.76 & 6.11 & 1.22 & -5.28 & -.24 & -2.26 & 24 & .033 \\
\hline
\end{tabular}

\begin{tabular}{|c|c|c|c|c|c|c|c|c|}
\hline & \multicolumn{5}{|c|}{ Paired Differences } & \multirow[t]{3}{*}{$\mathrm{t}$} & \multirow[t]{3}{*}{$\mathrm{df}$} & \multirow{3}{*}{$\begin{array}{l}\text { Sig. (2) } \\
\text { tailed) }\end{array}$} \\
\hline & \multirow[t]{2}{*}{$\begin{array}{c}\text { Mea } \\
\mathrm{n}\end{array}$} & \multirow[t]{2}{*}{$\begin{array}{c}\text { Std. } \\
\text { Devia } \\
\text { tion }\end{array}$} & \multirow[t]{2}{*}{$\begin{array}{l}\text { Std. } \\
\text { Error } \\
\text { Mean }\end{array}$} & \multicolumn{2}{|c|}{$\begin{array}{l}\text { 95\% Confidence } \\
\text { Interval of the } \\
\text { Difference }\end{array}$} & & & \\
\hline & & & & $\begin{array}{c}\text { Lowe } \\
\mathrm{r}\end{array}$ & Upper & & & \\
\hline $\begin{array}{c}\text { AidedRecallG1 } \\
- \\
\text { AidedRecallG2 }\end{array}$ & -1.24 & 5.93 & 1.19 & -3.69 & 1.21 & -1.05 & 24 & .31 \\
\hline
\end{tabular}




\begin{tabular}{|c|c|c|c|c|c|c|c|c|}
\hline \multicolumn{9}{|c|}{ Table 1: Descriptive - Unaided Recall of brand elements } \\
\hline & \multirow[t]{2}{*}{$\mathrm{N}$} & \multirow[t]{2}{*}{ Mean } & \multirow[t]{2}{*}{$\begin{array}{c}\text { Std. } \\
\text { Deviation }\end{array}$} & \multirow[t]{2}{*}{$\begin{array}{l}\text { Std. } \\
\text { Error }\end{array}$} & \multicolumn{2}{|c|}{$\begin{array}{l}\text { 95\% Confidence Interval for } \\
\text { Mean }\end{array}$} & \multirow[t]{2}{*}{ Minimum } & \multirow[t]{2}{*}{$\begin{array}{l}\text { Maxi } \\
\text { mum }\end{array}$} \\
\hline & & & & & $\begin{array}{l}\text { Lower } \\
\text { Bound }\end{array}$ & Upper Bound & & \\
\hline Group 1 & 25 & 21.2400 & 3.53883 & .70777 & 19.7792 & 22.7008 & 14.00 & 29.00 \\
\hline Group 2 & 25 & 21.2400 & 5.72480 & 1.14496 & 18.8769 & 23.6031 & 9.00 & 31.00 \\
\hline Group 3 & 25 & 16.6800 & 4.48813 & .89763 & 14.8274 & 18.5326 & 8.00 & 24.00 \\
\hline Group 4 & 25 & 20.8000 & 3.91578 & .78316 & 19.1836 & 22.4164 & 11.00 & 30.00 \\
\hline Total & 100 & 19.9900 & 4.82731 & .48273 & 19.0322 & 20.9478 & 8.00 & 31.00 \\
\hline
\end{tabular}

\begin{tabular}{|c|c|c|c|c|c|}
\hline \multicolumn{7}{|c|}{ Table 2: ANOVA - Unaided Recall of brand elements } \\
\hline & Sum of Squares & df & Mean Square & F & Sig. \\
\hline Between Groups & 368.430 & 3 & 122.810 & 6.082 & .001 \\
\hline Within Groups & 1938.560 & 96 & 20.193 & & \\
\hline Total & 2306.990 & 99 & & & \\
\hline
\end{tabular}

\begin{tabular}{|c|c|c|c|c|c|c|c|c|}
\hline \multicolumn{7}{|c|}{ Table 3: Descriptive - Aided Recall of brand elements } \\
\hline & N & Mean & $\begin{array}{c}\text { Std. } \\
\text { Deviatio } \\
\mathrm{n}\end{array}$ & Std. Error & $\begin{array}{c}95 \% \text { Confidence Interval } \\
\text { for Mean }\end{array}$ & $\begin{array}{c}\text { Minimu } \\
\mathrm{m}\end{array}$ & $\begin{array}{c}\text { Maximu } \\
\mathrm{m}\end{array}$ \\
\cline { 6 - 10 } & & & & & $\begin{array}{c}\text { Lower } \\
\text { Bound }\end{array}$ & $\begin{array}{c}\text { Upper } \\
\text { Bound }\end{array}$ & & \\
\hline Group 1 & 25 & 38.360 & 7.45475 & 1.49095 & 35.2828 & 41.4372 & 16.00 & 45.00 \\
\hline Group 2 & 25 & 36.040 & 10.06429 & 2.01286 & 31.8857 & 40.1943 & 16.00 & 45.00 \\
\hline Group 3 & 25 & 28.840 & 11.14181 & 2.22836 & 24.2409 & 33.4391 & 16.00 & 46.00 \\
\hline Group 4 & 25 & 39.640 & 10.67661 & 2.13532 & 35.2329 & 44.0471 & 16.00 & 47.00 \\
\hline Total & 100 & 35.720 & 10.64779 & 1.06478 & 33.6072 & 37.8328 & 16.00 & 47.00 \\
\hline
\end{tabular}

\begin{tabular}{|c|c|c|c|c|c|}
\hline \multicolumn{7}{|c|}{ Table 4: ANOVA - Aided Recall of bran elements } \\
\hline & Sum of Squares & df & Mean Square & F & Sig. \\
\hline Between Groups & 1744.320 & 3 & 581.440 & 5.888 & .001 \\
\hline .Within Groups & 9479.840 & 96 & 98.748 & & \\
\hline Total & 11224.160 & 99 & & & \\
\hline
\end{tabular}

